\title{
A data-driven network approach for characterization of political parties' ideology dynamics
}

\author{
Josemar Faustino ${ }^{* *}$ (D), Hugo Barbosa ${ }^{2}$, Eraldo Ribeiro ${ }^{1}$ and Ronaldo Menezes ${ }^{2}$
}

\author{
*Correspondence: \\ jcruz@biocomplexlab.org \\ ${ }^{1}$ Department of Computer \\ Engineering and Sciences, Florida \\ Institute of Technology, 150W \\ University Blvd., 32901 Melbourne, \\ FL, USA \\ Full list of author information is \\ available at the end of the article
}

\begin{abstract}
Political ideology is a major social phenomena that plays a crucial role in the formation and dynamics of ideologically-aligned social groups. This alignment gives rise to some of the most powerful social structures in modern democracies, the political parties. Due to the influence and importance of political parties in society, estimating their ideology is an active topic in political science research. However ideology is a very subjective phenomena and existing quantitative methods for ideology estimation are susceptible to a variety estimation issues, specially when applied in multi-partisan systems. In this work, we developed a data-driven network model for political ideology estimation based on partisan relationships established from party-switching politicians. The model is applied to the Brazilian case and yields results consistent with existing literature in the Brazilian political scenario while addressing data scarcity issues in existing methodologies.
\end{abstract}

Keywords: Ideology estimation, Political parties, Social networks, Group dynamics

\section{Introduction}

Political ideology plays a key role in democracies; it drives the formation and agenda of political parties; it also guides the voting decisions of citizens. Indeed, an effective strategy for a party to attract voters, and thus maximize its representation, is to align its political ideology and agenda with that of voters. This alignment strategy works because people tend to make voting decisions by matching their own opinions to a party's perceived ideology (Colomer 2004). By determining a party's ideology, citizens can make informed decisions in elections, which should improve the quality of political representation, and possibly contribute to a healthier democracy.

The development of methods for estimating the ideology of political parties is of major interest in political and social-economic sciences (Budge 2000; La Palombara and Weiner 1966). However, estimating ideology is highly subjective (Freeden 2006; Feldman and Johnston 2014). For instance, the meaning of ideological labels such as left, right, liberal, conservative depends on historical context, e.g., being a liberal in 1950 differs from being a liberal in 2019 (McCarty 2011). In fact, even a simplistic left-right characterization still leads to a continuous spectrum of orientations.

(c) The Author(s). 2019 Open Access This article is distributed under the terms of the Creative Commons Attribution 4.0 International License (http://creativecommons.org/licenses/by/4.0/), which permits unrestricted use, distribution, and reproduction in any medium, provided you give appropriate credit to the original author(s) and the source, provide a link to the Creative Commons license, and indicate if changes were made. 
Despite its subjectivity, partisan ideology can be estimated by quantitative approaches (Slapin and Proksch 2008; Clinton et al. 2004; Dinas and Gemenis 2010). The most popular class of approaches known as roll-call models rely on roll-call records of parliamentary voting (Hinich and Munger 1992). Roll-call models are usually applied to infer ideal points (e.g., most preferred outcomes) of individual politicians. Because of their popularity, they became very common to estimate the ideology of entire political parties. This is accomplished by aggregating the individual scores by their respective party. However, this method can lead to inaccurate estimates due to roll-calls with few records for certain cases (Poole and Rosenthal 2001). For example, roll-call data scarcity is an issue for countries with small parties with little representation as in the case of some major democracies (e.g. Argentina, Brazil, France, Germany, Mexico, Netherlands, and Switzerland). Roll-call based approaches cannot be applied in the case of new parties because they have no representation or in the case of newly elected politicians as their roll-call data is nonexistent.

In this paper, we present a quantitative approach based on network science (Barabási 2013) and grounded in assumptions from structural social-influence theory (Friedkin and Johnsen 2011) to estimate political parties' ideology. Here, we consider political parties as social groups, and we model partisan ideology based on party-switching affiliations from one election to another. Because our model does not use roll-call data, it can estimate ideal points of any political party in multi-party democracies regardless of the parties' parliamentary representation size.

Our contribution are as follows. First, we mine a large longitudinal dataset of electoral data to build networks of political parties based on politicians' party-switching affiliations. Second, we apply a community detection algorithm to uncover the macroscopic structure of the networks regarding partisan ideology. Third, by leveraging the network structure, we derive a model to estimate the ideology of political parties in the left-right scale. And finally, we validate our methods by probing the networks against a configuration model and comparing the distribution of ideological distances produced by the model in the case of empirical and synthetic networks.

Our approach applies a network science methodology to fill the gap of ideal-point estimation in multi-party democracies by demonstrating that election data, which includes data related to non-elected politicians, may still be effective in ideology estimation and are less likely to present data scarcity issues.

\section{Related works}

Quantitative methods estimating party ideology can be divided into two groups. Methods in the group estimate ideology by analyzing the party's manifestos and other foundation documents (Slapin and Proksch 2008; Dinas and Gemenis 2010). However, methods in this first group might suffer from two issues. First, the party's documents may reflect their author's opinions which may differ from the party's current ideology. This difference affects ideological estimation for large political parties. Second, analyzing manifestos to infer ideology can fail to capture longitudinal ideological variations.

The second group of quantitative methods estimate politicians' ideal points from rollcall records using approaches such as the Bayesian ideal-points estimation and the three-step nominate (Kellermann 2012; Clinton et al. 2004). Both approaches rely on existing voting records and are known to predict accurate voting outcomes. The Bayesian 
method is similar to the item-response model (i.e., the Rash model) largely used in education research (Bafumi et al. 2005). The nominate method is the most-used approach for ideology estimation. It combines the uncertainty of voting outcomes with a utility function that minimizes the distance from a legislator's ideal point and the bill being considered. The nominate method has been applied beyond parliamentary systems in analysis of the United Nations Assembly (Voeten 2000) and the United States Supreme Court (Martin and Quinn 2002). Both Nominate (and its variations) and the Bayesian methods are flexible and accurate and have been shown to generate similar results (Clinton and Jackman 2009). These methods are designed to uncover ideology at the individual level, yet, they are commonly used to analyze the ideology of political parties through aggregation of politician's ideology scores by party affiliation. This is the case of ideology studies of the European (Hix 2002) and Canadian Parliaments (Godbout and Høyland 2011); Argentina's (Alemán et al. 2018), Mexico's (Knight 2018) and Brazil's Chamber of Deputies (Bernabel 2015), and of the Brazilian Senate (McDonnell 2017). However, these methods' application to multiparty systems is limited because of the reliance of roll-call data, which is not always available.

The nominate approach was designed for two-party systems, yet the method can been used in multi-partisan democracies with some adaptations. For instance, a governmentopposition spectrum can be used instead of the left-right spectrum (Hix and Noury 2016). In previous works, this method was used with data from the Brazilian House of Representatives to estimate legislator's ideal points in a scale of support-opposition to the government (de Borja and Freitas 2015). While such an approach can be extrapolated to position a party with respect to its support (or opposition) to the government's position, it does not capture its ideological position. The nominate method also works for estimating ideal points for major political parties, but it is unsuitable for estimating ideology of small and newly created parties.

\section{Methods}

Our approach for estimating the ideology of political parties is based on the theory of social influence which posits that people's idiosyncrasies are affected by their social interactions. Likewise, the overall behavior of social groups is affected by its membership dynamics (Friedkin and Johnsen 2011). Here, we assume that the ideology of a political party as a social group, is affected by affiliation switches of politicians.

\section{Network model of party affiliation switching}

To test our assumptions, we model a network representing political parties and their affiliation dynamics as shown in Fig. 1. The network includes a temporal dimension to account for affiliation switches occurring at any election year. Each political party is represented as a node and any two parties are connected by an edge if at least one candidate switched affiliation from one party to the other. The edge only exists in the election year that the switch occurred, and the edge weight accounts for the number of switching politicians between the two parties (Filho et al. 2013).

Formally, let $V=\{1, \ldots, P\}$ be the set of political parties and $G^{y}=(V, E)$ be the affiliation-switch graph. A directed weighted edge $(i, j)^{y} \in E$ connects party $i$ to party $j$ if there exists a candidate who switched affiliation from party $i$ to party $j$ in the election cycle year $y$. The weight $w_{i j}^{y}$ is the total number of candidates switching from $i$ to $j$ in year $y$. 


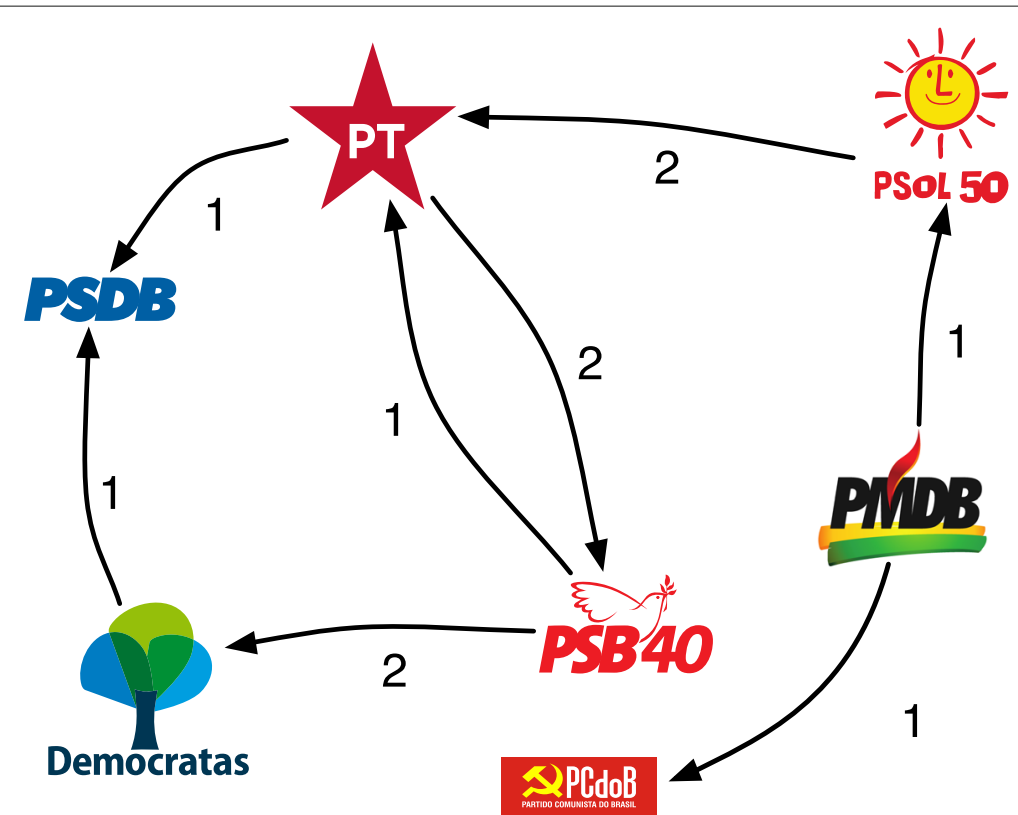

Fig. 1 The movement of candidates between parties yields a network of parties. Each candidate movement generates a connection between two parties. The result is a network where nodes represent parties and edges represent the connections among them. The weight $w_{i j}^{y}$ of an edge represents the total number of candidates switching from $i$ to $j$ in year $y$. See Additional file 1: Table S2 for details about the political parties studied in this paper

For example, assuming a candidate $c$, three parties $p_{1}, p_{2}$, and $p_{3}$, and three election years, $y_{1}, y_{2}$, and $y_{3}$, where $y_{1}<y_{2}<y_{3}$. A few scenarios can occur:

- If a candidate $c$ runs in election year $y_{1}$ for party $p_{1}$, and in elections years $y_{2}$ and $y_{3}$ for party $p_{2}$, the movement yields one directed edge $\left(p_{1}, p_{2}\right)$ for year $y_{2}$. There is no contribution to the graph for year $y_{3}$ from $c$ staying in the same party $\left(p_{2}\right)$ in years $y_{2}$ and $y_{3}$.

- If a candidate $c$ runs in election $y_{1}$ for party $p_{1}$, in $y_{2}$ for party $p_{2}$, and in $y_{3}$ for party $p_{3}$, the movements will yield edge $\left(p_{1}, p_{2}\right)$ for year $y_{2}$ and edge $\left(p_{2}, p_{3}\right)$ in the party graph for year $y_{3}$.

- If a candidate $c$ runs in election $y_{1}$ for party $p_{1}$, does not run in election $y_{2}$, and runs in election $y_{3}$ for party $p_{2}$, such movement yields one edge $\left(p_{1}, p_{2}\right)$ in the graph for the year $y_{3}$. This means the movement is only consolidated when the candidate reappeared in election $y_{3}$.

\section{Dataset}

We used a dataset of more than two million candidacies in Brazil (legislative and executive) from 1998 to 2018. The raw data is provided by the Brazilian Department of Elections ${ }^{1}$ and is freely available online.

We mined the dataset to retrieve affiliation switches. Then we generated ten networks, one for each election year, according to the scheme described in "Network model of party affiliation switching" section and Fig. 1. We found a total of 392,457 affiliation switches within twenty years of election data. A summary of each network is provided in Table 1. 
Table 1 Summary of the network characteristics for each election cycle

\begin{tabular}{llll}
\hline Election Year & Nodes & Edges & Total number of switches \\
\hline 2000 & 29 & 438 & 1512 \\
2002 & 30 & 561 & 3146 \\
2004 & 30 & 695 & 73,296 \\
2006 & 32 & 651 & 4591 \\
2008 & 32 & 736 & 85,337 \\
2010 & 32 & 640 & 4127 \\
2012 & 34 & 814 & 89,344 \\
2014 & 37 & 784 & 5587 \\
2016 & 38 & 1100 & 117,667 \\
2018 & 38 & 1004 & 7850 \\
\hline
\end{tabular}

\section{Structural evidence via community analysis}

Community detection to analyze the political scenario and its ideology dynamics has been recently investigated using roll-call data (Gomes Ferreira et al. 2018). In this work, we investigated the properties of the party-switching networks with regards to community structure and partisan ideology. A community is a set of nodes more tightly connected among themselves than to the rest of the network (Santo 2010). In the context of political networks defined by affiliation switches, a community means a group of parties sharing a higher rate of member exchange.

There are many methods of community detection, however, few of them support directed and weighted networks (Hartman et al. 2017). In this work, we applied the stochastic block model (SBM) for community detection (Peixoto 2014) because it satisfies both direction and edge weights. SBM applies an inference-based approach to find the best grouping ensemble of nodes by using entropy minimization (Karrer and Newman 2011), and is considered a state-of-art method for community detection (Peel et al. 2017). Furthermore, SBM has been shown to be equivalent (Newman 2016) to modularity based algorithm such as the Louvain method (Blondel et al. 2008).

We measured the ideological homogeneity among parties within communities to test the relationship between communities and ideological positions. Communities were assigned to the predominant position of parties within them (according to Table 2). When a party has a position different from the predominant of the community we accounted it as a miss. The proportion between the sum of all misses in a network and the total number of parties in it, is the measure of ideological influence on candidates movements, and is represented as a matching percentage.

Table 2 Parties classification based on their positions in the left-right ideological continuum as proposed by Miguel and Machado (Miguel and Machado 2007)

\begin{tabular}{lll}
\hline Left & Center & Right \\
\hline PT,PCB, PSTU & PMDB, PSDB & PP, PPB, PPR \\
PCdoB, PCO, PDT & & PFL, PRN \\
PHS, PMN, PPS & PDC, PL, PTB \\
PSB, PSTU, PV & PSDC, PSC, \\
& PGT, PRP, PAN, \\
& PSL, PTdoB, PSD, \\
& PRONA, PST \\
\hline
\end{tabular}

Party name details provided in Additional file 1: Table S2 


\section{Ideology of political parties}

We represent the ideology of individual party members as a value in a one-dimension leftright ideological continuum, where 1 denotes the extreme left, and 10 the extreme right, a convention largely adopted in the literature. Also following the political-science literature, we model parties' ideology using a normal distribution $\mathcal{N}(\mu, \sigma)$, where the mean $\mu$ is the party ideological center, and the standard deviation $\sigma$ is the ideological spread of party members (Fig. 2).

We assume that the switches in party affiliation by politicians ("Network model of party affiliation switching" section), when accounted at a sufficiently large scale (e.g., country level), should influence the ideologies of both the origin and the destination parties. These assumptions are grounded in many studies in social networks that investigated the effects of affiliation switches among social groups (e.g., company board interlocks) (Carpenter and Westphal 2001; Gulati and Westphal 1999).

The ideology of the party of origin is affected by the loss of its members, and the ideology of the destination party is affected by the new members' arrival. We also assume that the degree of change in party ideology resulting from affiliation switches is a function of the magnitude of the movement (e.g., the number of politicians), the ideological distance between the two parties, and, the size (e.g., number of running politicians) of both origin and destination parties. We further assume that politicians switch parties because their own ideology aligns better with the destination party. We think that this ideological-affinity assumption is reasonable given the large scale of our analysis, even though there can be many reasons for a politician to switch parties. Since our data include all candidates to all elected positions, sporadic affiliation switches that happen contrary to politicians' ideological affinity should have their influences averaged out leaving mostly ideology influences as a net result.

We modeled party switches by applying a sampling procedure. Since the ideology of each party is represented by $\mathcal{N}(\mu, \sigma)$, we can sample the moving members out of the origin party, and merge them into the destination party. To account for the ideological affinity of the leaving members with the destination party, we skew the sampling area in the party of origin towards the direction of the destination party. Here, the skewed sampling probability is given by a Beta distribution $\mathcal{B}(\alpha, \beta)$ with probability density function defined as:

$$
f(x ; \alpha, \beta)=\frac{1}{B(\alpha, \beta)} x^{\alpha-1}(1-x)^{\beta-1},
$$

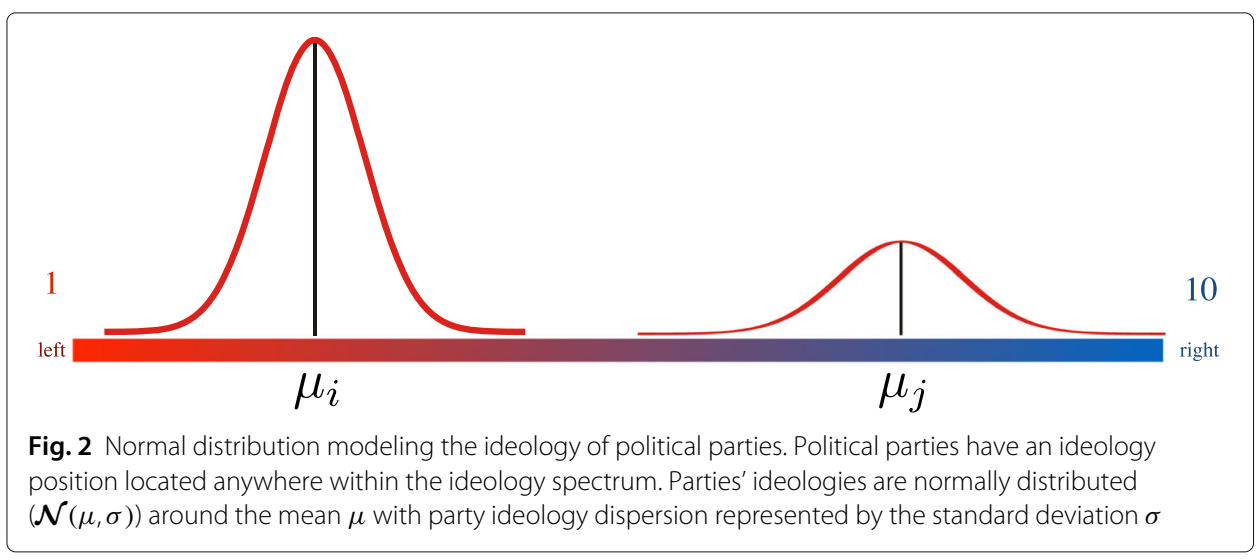


where:

$$
B(\alpha, \beta)=\frac{\Gamma(\alpha) \Gamma(\beta)}{\Gamma(\alpha+\beta)},
$$

and $\Gamma(\alpha)$ is the standard gamma function, given by:

$$
\Gamma(\alpha)=\int_{0}^{\infty} x^{\alpha-1} e^{-x} d x .
$$

Formally, let $\mathcal{N}\left(\mu_{i}, \sigma_{i}\right)$ and $\mathcal{N}\left(\mu_{j}, \sigma_{j}\right)$ be ideology distributions of the origin and destination parties, respectively. We define the parameters $(\alpha, \beta)$ of the Beta distribution proportional to the ideological distance between the parties, defined as $\left|\mu_{i}-\mu_{j}\right|$. The relationship between $\alpha$ and $\beta$ is defined as follows:

$$
\left\{\begin{array}{l}
\alpha>\beta, \text { if } \mu_{i}>\mu_{j} \\
\alpha<\beta, \text { if } \mu_{i}<\mu_{j} \\
\alpha=\beta, \text { if } \mu_{i}=\mu_{j} .
\end{array}\right.
$$

For all cases, we set $\alpha, \beta \in[1,10]$, with the variation in between determined by the ideological distance $\left|\mu_{i}-\mu_{j}\right|$. When $\alpha>\beta$, we set $\alpha=10$, and $\beta \propto\left|\mu_{i}-\mu_{j}\right|$. The opposite case works similarly, for $\alpha<\beta$, we set $\beta=10$, and $\alpha \propto\left|\mu_{i}-\mu_{j}\right|$. For cases when parties have the same ideology score, we set $\alpha=\beta=10$. Any configuration of $\alpha$ and $\beta>1$ yields a similar behavior of the Beta distribution. The choice of the $0-10$ range maintains the consistency with the adopted ideology range (Power and Zucco Jr 2009). The three cases (Eq. 4) skew the sampling area to the left, to the right, or the same as the distribution of the origin party $\mathcal{N}\left(\mu_{i}, \sigma_{i}\right)$, which occurs when $\alpha=\beta$ and $\alpha>1$. The first two cases are depicted in Fig. 3.

As politicians switch from one party to another, we sample from the origin party $\mathcal{N}\left(\mu_{i}, \sigma_{i}\right)$ and add to the destination $\mathcal{N}\left(\mu_{j}, \sigma_{j}\right)$. At every interaction (election year), we keep a table with the number of running politicians and position of every party. The size of each party's pool of members is adjusted at every iteration (i.e., election cycle), to be the number of politicians running in that party for any election year. We initialized the model with means and standard deviation using elite survey data reported by Zucco and Power (Power and Zucco Jr 2009), as shown in Additional file 1: Table S1. The procedure was repeated for all election years in the dataset.
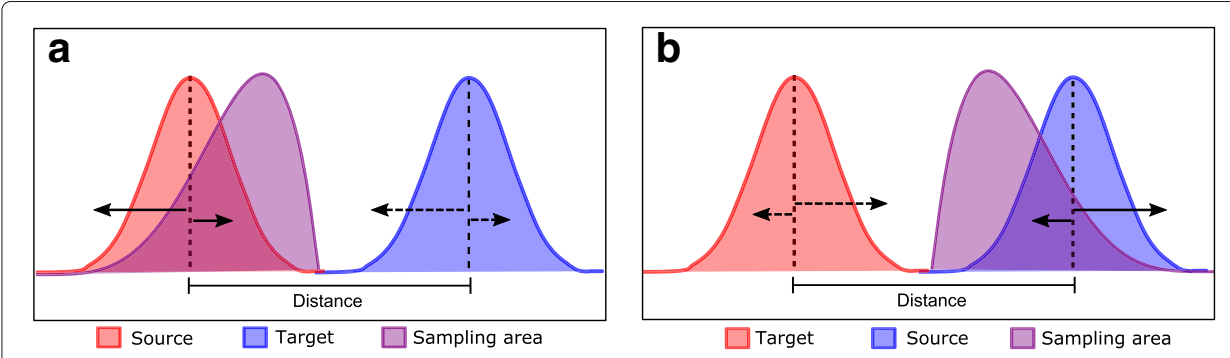

Fig. 3 Sampling of switching politicians based on ideological distance following a Beta Distribution $\boldsymbol{B}(\alpha, \beta)$. The parameters $\alpha$ and $\beta$ which are proportional to the distance between the origin and destination means $\left(\mu_{i}, \mu_{j}\right.$ see Fig. 2$)$ are shown as vertical dashes. The longer horizontal arrows show the most likely shift in ideology. Because the model is probabilistic, there is also a possibility of the shift occurring in the opposite direction (shorter arrows). Continuous horizontal arrows represent the shift in the origin party while dashed arrows represent the shift in the destination party. In panel $\mathbf{a}$, the destination party is on the right, hence the politicians on the right side of the origin distribution are more likely to leave. Conversely, in panel $\mathbf{b}$ the destination party is on the left, hence the politicians on the left side of the origin distribution are more likely to leave 


\section{Comparison with a configuration model}

The input of the ideology model are graphs representing the switching patterns of politicians among the political parties. To assess our model's ability to capture structural components of the party switching networks, we compared it with a randomized configuration model (Fosdick et al. 2018).

For each graph, we generated a randomized counterpart by shuffling the edges and maintaining the degree distribution. For each election year and for each affiliation switch, we fixed the origin party and sampled the destination with replacement from the set of active political parties in that year. This procedure creates parallel edges, which are then collapsed into edge weights. The method yields one randomized graph for each election, which are input into the ideology model described in "Ideology of political parties" section. The distributions of random and empirical graphs are shown in Fig. 6.

\section{Results}

The outcome of the community detection analysis suggests that inter-party migrations are coherent with the party ideology. As shown in Fig. 4, the networks became more representative of the switching phenomena over time as increasingly more switching information is mined from electoral data. However, the high matching rates shown in Table 3 were unexpected due to the higher density of later years' networks (e.g., 2016 and 2018), in addition to an alleged lack of strong ideological roots for most of the political parties in Brazil (Zucco 2009).

The community detection analysis shows a tendency of parties of similar ideology appearing together. This structure also shows a type of ideological locality, i.e., despite changing affiliations, the majority of politicians tend to move to groups that are ideologically closer to those with which they have been previously affiliated. Such a structure is indicative of the existence of ideological affinity in affiliation exchanges among parties and provides ground to the assumptions in our model of parties' ideology.

Underlying our modeling assumptions is the consideration of political parties as social groups. These groups interact with each other through affiliation exchanges which were aggregated every election year. On each interaction, the group's ideology was recomputed based on the positions of the incoming and outgoing members (e.g., the ideological position of a party in 2004 was used to compute its position in 2006). This allowed us to create a temporal trajectory of the political parties' ideologies as shown in Fig. 5.

Recomputing the ideology after every election cycle accounts for two important assumptions. The people joining the destination party will "integrate and blend in" with the party's ideology. Similarly, the new members bring their previous beliefs and idiosyncrasies into the group, thus, changing its ideology. These effects represents the bidirectional nature of social influence in which the group influences its new members whereas the new members also influence the group (Friedkin and Johnsen 2011).

The number of first time candidates and of candidates loyal to the party (candidates that never run in other parties) play an important role in party stability regarding ideology shifts. Large parties will be more stable since the size of the influx of members, which translates into ideology changes, is proportional to its size. That is, a party with a high proportion of loyal and new members in its pool of members is less susceptible to ideology shifts. Conversely, when a small party receives a high number of new members, proportional to its size, such party is likely to suffer a significant change in its ideological leaning 

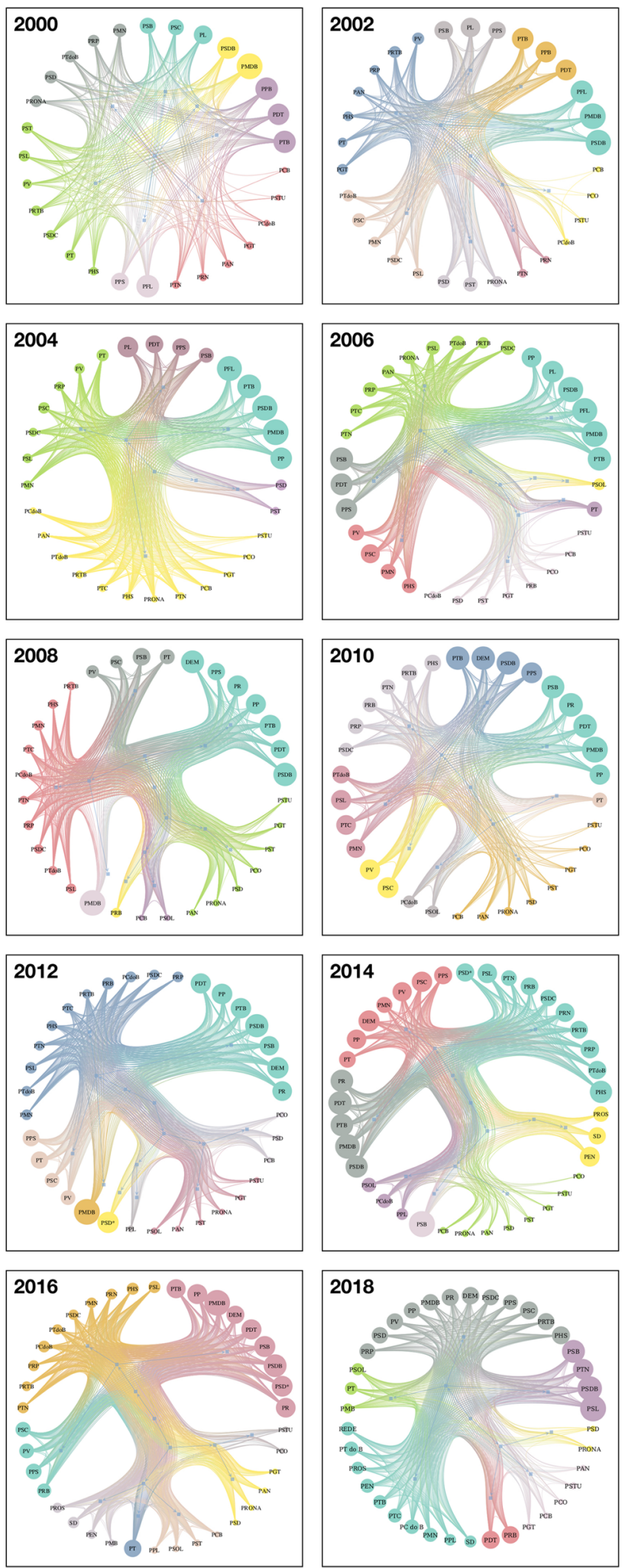

Fig. 4 Networks of inter-parties movements for the elections in the period from 2000 to 2018. The nodes' colors correspond to their communities while sizes are proportional to the nodes' total weighted degree. In the first year, the network has low density and there is scant evidence of structure. As more data is added the structure of party clusters became evident 
Table 3 Communities and the matching rate to the political ideological position described in Table 2

\begin{tabular}{lll}
\hline Network & \# Communities & $\%$ Matching \\
\hline 2000 & 7 & $69.5 \%$ \\
2002 & 6 & $80.8 \%$ \\
2004 & 8 & $73.2 \%$ \\
2006 & 6 & $79.8 \%$ \\
2008 & 6 & $68.2 \%$ \\
2010 & 8 & $71.5 \%$ \\
2012 & 6 & $63.4 \%$ \\
2014 & 6 & $73.1 \%$ \\
2016 & 7 & $73.2 \%$ \\
2018 & 7 & $60.0 \%$ \\
\hline
\end{tabular}

The \% matching is computed by the number of correctly classified parties (for all communities) divided by the number of parties in the network

as a result of the influence of the new members. Additionally, this effect is proportional to the ideological position from which the incoming members originated.

Our model captures interesting events in the party dynamics of Brazilian politics. It is not our intent to delve into the field of comparative politics, to which we refer the interested reader to an excellent accounts in comparative analysis of Brazilian contemporary politics (Power 2011; Bruera 2013). Nevertheless, we point out the results of our model that remarkably captured or anticipated important developments in the Brazilian political landscape. One example of these events was a split that occurred within the Workers Party (PT) in 2005 when many of its affiliates left the party to create the Party of Freedom and Socialism (PSOL). As a new party, the PSOL had very few elected officials, making it impractical the use of roll-call data models to evaluate the party's location in the political ideological spectrum (Poole 2000). Our model placed the PSOL close to the position of

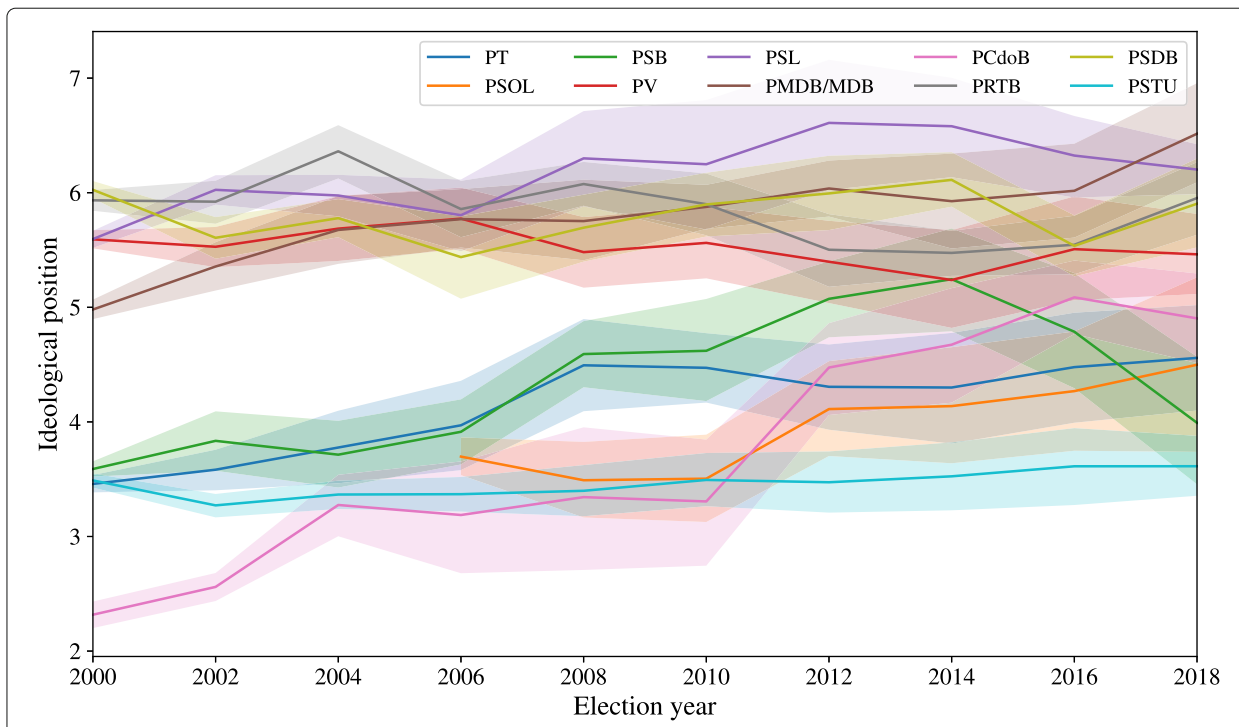

Fig. 5 Positions of political parties. The starting points from Zucco and Power (Power and Zucco Jr 2009) (Additional file 1: Table S1) are from the election year of 1998. The points shown for year 2000 are already computed from our model. The points of interest are the location of the party in any election year. The error of each score is shown with the same color in higher transparency. Movements to the left or to the right along the ideological spectrum represents the dynamics of the churn rate of members in any election year. The stability of a party to its current ideology depends on the number of loyal and newly acquired members 
the Worker's party, from which most of its members came. Not surprisingly, a few years later, the position of PSOL was quantitatively estimated as a left-wing party using roll-call data (Zucco JR and Lauderdale 2011), in agreement with our predictions.

Another interesting observation was the rightward movement of the PSB (Socialist Party of Brazil). Notice in Fig. 5 that in the beginning of the 2000's, PSB was a left-wing party. Our model shows a rightward movement which is also mentioned by comparative politics analysis (Power and Zucco Jr 2009; Miguel and Machado 2007). PSB's right shift coincides with a key moment of Brazilian politics in modern times, which was the impeachment of the left-leaning president Dilma Roussef (Nunes and Melo 2017). In this period, the PSB joined forces against the party of Mrs. Roussef, and the party voted overwhelmingly to oust her from power both in the House and in the Senate. Since then, the party has been often split on whether or not to support the reforms proposed by the subsequent president Michel Temer. Our model suggests that PSB lost most of its right-leaning members, pushing the party's ideology back to the left.

Our validation experiments aimed at ensuring that our model captures the structural characteristics observed in the network. Figure 6 shows the empirical and shuffled distributions of distances of affiliation switches for all election years. The configuration methodology yields a distribution of distances centered in the middle of the ideology spectrum because the targets are randomly sampled out of all parties active in a given year. On the other hand, the distribution of distances from the empirical data shows a clear tendency of shorter distances, consistent with the community detection analysis.

\section{Final considerations}

Political parties are an essential component of modern democracies. Hence, understanding their dynamics and characteristics is paramount. In this work, we proposed an approach to estimate the ideology of political parties based on their members' affiliation exchanges. We show that our methods can capture the ideology of new or lessrepresented political groups, a scenario in which traditional methodologies could not be applied. Our model can position parties in the ideological spectrum regardless of their size or level of representation as long as affiliation data is available. To test our model, we identified affiliation switches by mining a large longitudinal dataset from Brazilian elections, where party-switching affiliations is a well-known behavior among politicians (Desposato 2006).

In this work, we showed that our results are consistent with the phenomena of ideological locality by comparing the empirical results with a network configuration model. However, our model is suitable for uncovering a macro view of the political landscape. Unlike roll-call data models, our methods are not suited to estimate ideal points at an individual level, which can be adjusted for both individual and group level studies. Furthermore, the applicability of our method is suited to situations in which the roll-call data is scarce for certain political parties in multi-partisan systems.

An important aspect of our work, is its potential to be generalized to any social groups. There are many cases of well-structured groups in which affiliation switches play a role in the group's general characteristics such as academics in research institutions and dynamics of employees in companies. Modeling social group characteristics from members affiliation dynamics can potentially leverage the knowledge of several underlying social phenomena. 


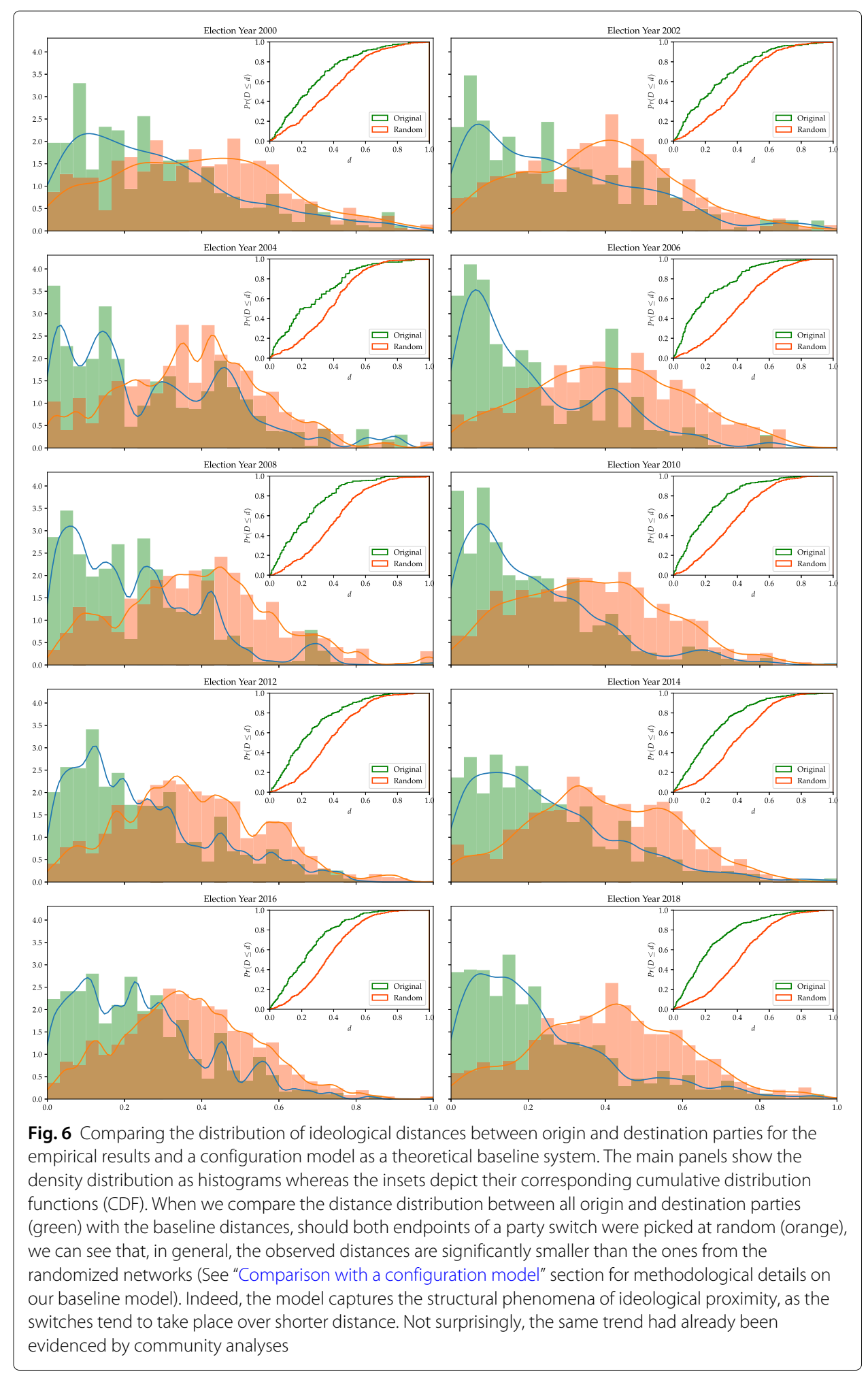




\section{Endnote}

${ }^{1}$ http://www.tse.jus.br

\section{Additional file}

Additional file 1: Ideological positions and party details tables. (PDF 19,672 kb)

\section{Abbreviations}

CDF: Cumulative Distribution Function; PSB: Socialist Party of Brazil; PSOL: Socialism and Freedom Party; PT: Workers Party; SBM: Stochastic Block Model Additional details of all Brazilian parties in this study are presented in Additional file 1: Table S2

\section{Acknowledgments}

The authors would like to thank all BioComplex lab members, Amanda de Oliveira, Leto Peel, and the anonymous reviewers for helpful comments and suggestions.

\section{Authors' contributions}

$J F, H B$, ER and RM designed the study. JF collected the data and performed the experiments, JF, HB, ER and RM wrote the manuscript, ER, HB, and RM revised the manuscript for intellectual content. All authors read and approved the final version of the manuscript.

\section{Funding}

Josemar Faustino is supported by the Science Without Borders program (CAPES, Brazil) under grant 99999.001043/2014-05. Part of this work was created in computing infrastructure supported by the National Science Foundation under Grant No. CNS 09-23050. This work was partially supported by the Army Research Office under grant W911NF-17-1-0127-P00001. The funding agencies had no role in any part of the design, data collection, analysis, interpretation of results, or writing of the manuscript. Publication of this article was funded in part by the Open Access Subvention Fund and the John H. Evans Library.

\section{Availability of data and materials}

All datasets used in this work are freely available at http://www.tse.jus.br/eleicoes/estatisticas/(in Portuguese). Intermediary files and code are available upon request to the corresponding author.

\section{Competing interests}

The authors declare that they have no competing interests.

\section{Author details}

${ }^{1}$ Department of Computer Engineering and Sciences, Florida Institute of Technology, 150 W University Blvd., 32901

Melbourne, FL, USA. ${ }^{2}$ Department of Computer Science, University of Exeter, Exeter, EX4 4QD, UK.

Received: 17 February 2019 Accepted: 19 June 2019

Published online: 16 July 2019

\section{References}

Alemán E, Micozzi JP, Pinto PM, Saiegh S (2018) Disentangling the role of ideology and partisanship in legislative voting: Evidence from argentina. Legis Stud Q 43(2):245-273. https://doi.org/10.1111/lsq.12182

Bafumi J, Gelman A, Park DK, Kaplan N (2005) Practical Issues in Implementing and Understanding Bayesian Ideal Point Estimation. Political Anal 13(02):171-187. https://doi.org/10.1093/pan/mpi010

Barabási A-L (2013) Philos Trans Royal Soc A: Math Phys Eng Sci 371(1987):20120375. https://doi.org/10.1098/rsta.2012. 0375

Bernabel R (2015) Does the electoral rule matter for political polarization? The case of Brazilian legislative chambers. Braz Polit Sci Rev 9(2):81-108. https://doi.org/10.1590/1981-38212014000200012

Blondel VD, Guillaume J-L, Lambiotte R, Lefebvre E (2008) Fast unfolding of communities in large networks. J Stat Mech Theory Exp 2008(10):10008. http://dx.doi.org/10.1088/1742-5468/2008/10/P10008

Bruera HFG (2013) Lula, the Workers' Party and the Governability Dilemma in Brazil. Routledge Studies in Latin American Politics (Book 7). Routledge, New York USA. https://doi.org/10.4324/9780203493984

Budge I. (2000) Expert judgements of party policy positions: uses and limitations in political research. Eur J Polit Econ Res 37(1):103-113. https://doi.org/10.1111/1475-6765.00506

Carpenter MA, Westphal JD (2001) The strategic context of external network ties: Examining the impact of director appointments on board involvement in strategic decision making. Acad Manag J 44(4):639-660. https://doi.org/10. $5465 / 3069408$

Clinton JD, Jackman S (2009) To simulate or nominate? Legis Stud Q 34(4):593-621. https://doi.org/10.3162/ 036298009789869691

Clinton J, Jackman S, Rivers D (2004) The Statistical Analysis of Roll Call Data. Am Political Sci Rev 16:355-370. https://doi. org/10.1017/S0003055404001194

Colomer JM (2004) The Strategy and History of Electoral System Choice. In: Colomer JM (ed). The Handbook of Electoral System Choice. Palgrave Macmillan UK, London. pp 3-78. https://doi.org/10.1057/9780230522749_1

de Borja FG, Freitas CMDS (2015) CivisAnalysis: Interactive Visualization for Exploring Roll Call Data and Representatives' Voting Behaviour. In: 28th Conference on Graphics Patterns and Images (SIBGRAPI). pp 257-264. https://doi.org/10. 1109/SIBGRAPI.2015.34 
Desposato SW (2006) Parties for rent? ambition, ideology, and party switching in brazil's chamber of deputies. Am J Polit Sci 50(1):62-80. https://doi.org/10.1111/j.1540-5907.2006.00170.x

Dinas E, Gemenis K (2010) Measuring Parties' Ideological Positions With Manifesto Data: A Critical Evaluation of the Competing Methods. Party Politics 16(4):427-450. https://doi.org/10.1177/1354068809343107

Feldman S, Johnston C (2014) Understanding the determinants of political ideology: Implications of structural complexity. Political Psychology 35(3):337-358. https://doi.org/10.1111/pops.12055

Filho H. B., Faustino J., Martins R. R., Menezes R. (2013) Strategies, political position, and electoral performance of brazilian political parties. In: 2013 BRICS Congress on Computational Intelligence and 11th Brazilian Congress on Computational Intelligence. pp 659-664. https://doi.org/10.1109/BRICS-CCI-CBIC.2013.115

Freeden M (2006) Ideology and political theory. J Political Ideologies 11(1):3-22. https://doi.org/10.1080/ 13569310500395834

Friedkin NE, Johnsen EC (2011) Social Influence Network Theory: A Sociological Examination of Small Group Dynamics. Structural Analysis in the Social Sciences. Cambridge University Press, Cambridge UK. https://doi.org/10.1017/ CBO9780511976735

Fosdick B, Larremore D, Nishimura J, Ugander J (2018) Configuring random graph models with fixed degree sequences. SIAM Rev 60(2):315-355. https://doi.org/10.1137/16M1087175

Godbout J-F, Høyland B (2011) Can J Polit Sci/Rev Can Sci Polit 44(2):367-388. https://doi.org/10.1017/ S0008423911000175

Gomes Ferreira CH, de Sousa Matos B, Almeira JM (2018) Social Informatics. In: Staab S, Koltsova O, Ignatov DI (eds). Springer, Cham. pp 257-273. https://doi.org/10.1007/978-3-030-01129-1_

Gulati R, Westphal JD (1999) Cooperative or controlling? the effects of ceo-board relations and the content of interlocks on the formation of joint ventures. Adm Sci Q 44(3):473-506. https://doi.org/10.2307/2666959

Hartman R, Faustino J, Pinheiro D, Menezes R (2017) Assessing the suitability of network community detection to available meta-data using rank stability. In: Proceedings of the International Conference on Web Intelligence - WI ' 17. ACM Press, New York, New York, USA. pp 162-169. https://doi.org/10.1145/3106426.3106493

Hinich MJ, Munger MC (1992) A Spatial Theory of Ideology. J Theor Polit 4(1):5-30. https://doi.org/10.1177/ 0951692892004001001

Hix S (2002) Parliamentary behavior with two principals: Preferences, parties, and voting in the european parliament. Am J Polit Sci 46(3):688-698. https://doi.org/10.2307/3088408

Hix S, Noury A (2016) Government-opposition or left-right? the institutional determinants of voting in legislatures. Polit Sci Res Methods 4(2):249-273. https://doi.org/10.1017/psrm.2015.9

Karrer B, Newman MEJ (2011) Stochastic blockmodels and community structure in networks. Phys Rev E 83:016107. https://doi.org/10.1103/PhysRevE.83.016107

Kellermann M (2012) Estimating Ideal Points in the British House of Commons Using Early Day Motions. Am J Political Sci 56(3):757-771. https://doi.org/10.1111/j.1540-5907.2012.00587.x

Knight RD (2018) Strategic Coalitions and Agenda-Setting in Fragmented Congresses: How the PRI Sets the Legislative Agenda in Mexico. Braz Polit Sci Rev 12. https://doi.org/10.1590/1981-3821201800020001

La Palombara J, Weiner M (1966) The Origin and Development of Political Parties. Princeton University Press, Princeton USA

Martin AD, Quinn KM (2002) Dynamic Ideal Point Estimation via Markov Chain Monte Carlo for the U.S. Supreme Court, 1953-1999. Polit Anal 10(02):134-153. https://doi.org/10.1093/pan/10.2.134

McCarty N (2011) Measuring Legislative Preferences. In: The Oxford Handbook of the American Congress. Oxford University Press, Oxford UK. p 57. https://doi.org/10.1093/oxfordhb/9780199559947.003.0004

McDonnell RM (2017) Formal Comparisons of Legislative Institutions: Ideal Points from Brazilian Legislatures. Braz Polit Sci Rev 11. https://doi.org/10.1590/1981-3821201700010007

Miguel LF, Machado C (2007) A delicate balance: the dynamics of the workers' party alliances in the Brazilian municipal elections (2000 and 2004). Dados - Revista de Ciências Sociais 50(4):757-793. https://doi.org/10.1590/5001152582007000400005

Newman ME (2016) Equivalence between modularity optimization and maximum likelihood methods for community detection. Phys Rev E 94(5):052315. https://doi.org/10.1103/PhysRevE.94.052315

Nunes F, Melo CR (2017) Impeachment, Political Crisis and Democracy in Brazil. Rev Ciencia Política 37(2). https://doi.org/ 10.4067/s0718-090×2017000200281

Peel L, Larremore DB, Clauset A (2017) The ground truth about metadata and community detection in networks. Sci Adv 3(5). https://doi.org/10.1126/sciadv.1602548

Peixoto T (2014) Hierarchical block structures and high-resolution model selection in large networks. Phys Rev X 4(1):1-18. https://doi.org/10.1103/PhysRevX.4.011047. http://arxiv.org/abs/1310.4377

Poole KT (2000) Nonparametric Unfolding of Binary Choice Data. Polit Anal 8(3):211-237. https://doi.org/10.1093/ oxfordjournals.pan.a029814

Poole KT, Rosenthal H (2001) D-nominate after 10 years: A comparative update to congress: A political-economic history of roll-call voting. Legis Stud Q 26(1):5-29. https://doi.org/10.2307/440401

Power T (2011) Corruption and Democracy in Brazil: The Struggle for Accountability (ND Kellogg Inst Int'I Studies)(Taylor MM, ed.). University of Notre Dame Press, Notre Dame USA

Power TJ, Zucco Jr C (2009) Estimating Ideology of Brazilian Legislative Parties, 1990-2005: A Research Communication. Lat Am Rev 44(1):218-246. https://doi.org/10.1353/lar.0.0072

Santo F (2010) Community detection in graphs. Phys Rep 486(3-5):75-174. https://doi.org/10.1016/j.physrep.2009.11.002. http://arxiv.org/abs/0906.0612

Slapin JB, Proksch S-O (2008) A Scaling Model for Estimating Time-Series Party Positions from Texts. Am J Political Sci 52(3):705-722. https://doi.org/10.1111/j.1540-5907.2008.00338.x 
Voeten E (2000) Clashes in the Assembly. Int Organ 54(2):185-215. https://doi.org/10.1162/002081800551154

Zucco C (2009) Ideology or what? Legislative behavior in multiparty presidential settings. J Polit 71(03):1076-1092. https://doi.org/10.1017/S0022381609090896

Zucco JR C, Lauderdale BE (2011) Distinguishing between influences on brazilian legislative behavior. Legis Stud Q 36(3):363-396. https://doi.org/10.1111/j.1939-9162.2011.00019.x

\section{Publisher's Note}

Springer Nature remains neutral with regard to jurisdictional claims in published maps and institutional affiliations.

Submit your manuscript to a SpringerOpen ${ }^{\circ}$ journal and benefit from:

- Convenient online submission

- Rigorous peer review

Open access: articles freely available online

- High visibility within the field

- Retaining the copyright to your article

Submit your next manuscript at $\boldsymbol{\triangleright}$ springeropen.com 